\title{
Effectiveness of interventions for reducing TB incidence in countries with low TB incidence: a systematic review of reviews
}

\author{
Simon M. Collin (10 ${ }^{1}$, Fatima Wurie ${ }^{1}$, Morris C. Muzyamba ${ }^{1}$, Gerard de Vries ${ }^{2}$, \\ Knut Lönnroth ${ }^{3}$, Giovanni Battista Migliori $\mathbb{1}^{4}$, Ibrahim Abubakar ${ }^{5}$, Sarah \\ R. Anderson ${ }^{1}$ and Dominik Zenner ${ }^{5}$
}

Affiliations: ${ }^{1}$ TB Unit, National Infection Service, Public Health England, London, UK. ${ }^{2}$ KNCV Tuberculosis Foundation, Den Haag, Netherlands. ${ }^{3}$ Karolinska Institutet, Stockholm, Sweden. ${ }^{4}$ Istituti Clinici Scientifici Maugeri IRCCS, Tradate, Italy. ${ }^{5}$ UCL Institute for Global Health, London, UK.

Correspondence: Simon Collin, TB Unit, National Infection Service, Public Health England, London, NW9 5EQ, UK. E-mail: simon.collinaphe.gov.uk

@ERSpublications

Whilst vaccination and treatment of latent TB infection are supported by review level evidence, there is a need for a stronger evidence base in other intervention areas to support decisions when formulating TB control policy in low-incidence countries. http://ow.ly/Y4vA50p4Hfv

Cite this article as: Collin SM, Wurie F, Muzyamba MC, et al. Effectiveness of interventions for reducing TB incidence in countries with low TB incidence: a systematic review of reviews. Eur Respir Rev 2019; 28: 180107 [https://doi.org/10.1183/16000617.0107-2018].

\section{ABSTRACT}

Aims: What is the evidence base for the effectiveness of interventions to reduce tuberculosis (TB) incidence in countries which have low TB incidence?

Methods: We conducted a systematic review of interventions for TB control and prevention relevant to low TB incidence settings ( $<10$ cases per 100000 population). Our analysis was stratified according to "direct" or "indirect" effects on TB incidence. Review quality was assessed using AMSTAR2 criteria. We summarised the strength of review level evidence for interventions as "sufficient", "tentative", "insufficient" or "no" using a framework based on the consistency of evidence within and between reviews.

Results: We found sufficient review level evidence for direct effects on TB incidence/case prevention of vaccination and treatment of latent TB infection. We also found sufficient evidence of beneficial indirect effects attributable to drug susceptibility testing and adverse indirect effects (measured as sub-optimal treatment outcomes) in relation to use of standardised first-line drug regimens for isoniazid-resistant TB and intermittent dosing regimens. We found insufficient review level evidence for direct or indirect effects of interventions in other areas, including screening, adherence, multidrug-resistant TB, and healthcareassociated infection.

Discussion: Our review has shown a need for stronger evidence to support expert opinion and country experience when formulating TB control policy.

This article has supplementary material available from err.ersjournals.com

Provenance: Submitted article, peer reviewed.

Received: Dec 042018 | Accepted after revision: March 222019

Copyright $\odot$ ERS 2019. This article is open access and distributed under the terms of the Creative Commons Attribution Non-Commercial Licence 4.0. 


\section{TABLE 1 Stratification of systematic reviews of interventions}

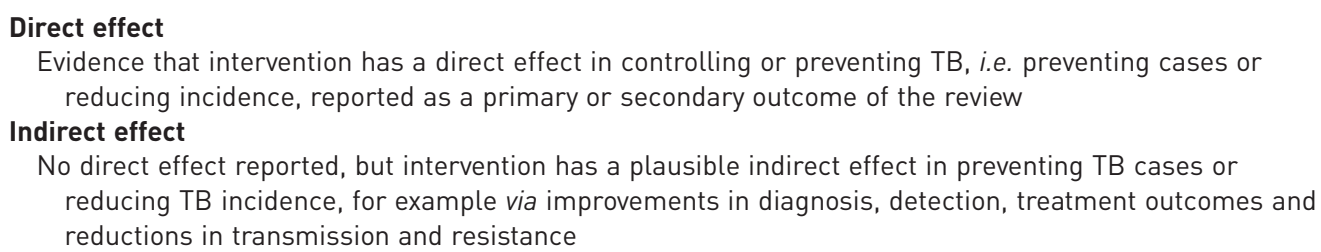

TB: tuberculosis.

\section{Introduction}

Projected trends indicate that a substantial strengthening of efforts to reduce tuberculosis (TB) incidence is needed if the World Health Organization (WHO) End TB strategy is to be met in countries of low TB incidence [1]. Whilst frameworks to accelerate the reduction in TB incidence can be reached by expert consensus [2,3], it is fundamental that these are underpinned by a robust and up-to-date evidence base for the effectiveness of specific interventions. Such an evidence base also allows for harmonisation of best-practice approaches to TB control between countries which have shared (or open) borders, such as across the European Union/European Economic Area (EU/EEA) [4-6].

Systematic reviews are a recognised method for compiling and assessing the findings of multiple systematic reviews into one accessible and usable summary of the evidence base [7,8]. The objective of the present review was: 1) to identify systematic reviews of interventions to reduce TB incidence and prevent TB cases in settings of low TB incidence; 2) to assess the quality of the reviews in relation to direct and indirect effects of the interventions on TB incidence; and 3) to summarise the overall strength of evidence for each reviewed intervention. We focused on reviews of interventions for which reduction in TB incidence and prevention of TB cases was a measurable outcome, but our broad definition of "intervention" also encompassed approaches to TB diagnosis and treatment which could have an indirect impact on TB incidence. The overall aim of the review was to provide an evidence base to inform the development and implementation of national TB plans.

\section{Methods}

This systematic review was conducted as part of the European Commission funded E-DETECT TB (Early Detection and Integrated Management of Tuberculosis in Europe) project, which aims to improve TB control efforts across Europe through translational research designed to reach high-risk groups in EU/EEA countries, as well as the development of a practical evidence-based toolkit to support development and implementation of national TB plans $[9,10]$. The review protocol was defined in advance and registered with PROSPERO (www.crd.york.ac.uk/prospero/ CRD42017060096).

\section{Inclusion and exclusion criteria}

Systematic reviews of interventions for TB control and prevention in settings of low TB incidence $(<10$ cases per 100000 population) were eligible [11]. We defined "intervention" as any population level, public health or clinical (at primary, secondary or tertiary level) activity which prevents further cases of active TB or latent TB infection (LTBI), and which has the potential to reduce the incidence of TB at local, regional or national level. This broad definition of "intervention" would include: actions specifically designed for/ targeted at TB control/case prevention; clinical approaches, such as different diagnostic methods and drug regimens; areas of activity defined by particular patient groups, e.g. HIV co-infected, multidrug-resistant (MDR)-TB, vulnerable groups, pregnant women, or settings such as healthcare facilities and prisons; and areas of action defined by level of intervention, e.g. social and healthcare systems. Our analysis was stratified by type of effect, distinguishing reviews of interventions which reported a quantifiable "direct effect" from those which had an "indirect effect" on reducing TB incidence or preventing TB cases (table 1). Pre-specified reasons for excluding reviews were: not a systematic review; no intervention evaluated; no direct or indirect effect in preventing TB cases/reducing TB incidence; and economic evaluation only (see Appendix S2 for inclusion checklist). We did not exclude systematic reviews which included studies set in countries with high TB incidence if the review included at least one study in a low TB-incidence setting. As an adjunct to our main analysis, we included reviews of "risk factors" which could modify the effects of interventions or which, if targeted in a hypothetical intervention, could lead to a reduction in TB incidence. Our aim with regard to risk factors was to highlight possible future areas for intervention, particularly those which currently fall outside conventional TB-focused public health or clinical approaches to reducing TB incidence or which could reduce or enhance the effectiveness of conventional interventions. 
Search methods for identification of reviews

The following databases were searched from inception to May 2017: MEDLINE, EMBASE, CINAHL, Scopus, Global Health, Trip, Cochrane Library, Social Policy and Practice, HMIC (Health Management Information Consortium), DoPHER (Database of Promoting Health Effectiveness Reviews), Health Systems Evidence and National Guideline Clearinghouse. In addition, the PROSPERO systematic reviews register and the International Journal of Tuberculosis and Lung Disease were searched within the same period. Full search strategies are shown in Appendix S1. In brief, we used a search filter developed by LEE et al. [12], combined with MeSH and title word terms for tuberculosis, mycobacterium and TB. To search databases of reviews, health evidence or guidelines, we simply used terms for tuberculosis/TB. No language or date restrictions were imposed.

\section{Selection of reviews}

Citations identified by the search were imported into EndNote (EndNote X8; Clarivate Analytics, Boston, MA, USA) for de-duplication, and then imported into to EPPI-Reviewer 4 (EPPI-Centre Software, Social Science Research Unit, UCL Institute of Education, London, UK) for further de-duplication and for screening. Two reviewers screened references by title and abstract, with any disagreements resolved by discussion with a third reviewer. Full texts of all articles identified in the second screen by title and abstract were retrieved. The full texts of retrieved articles were screened for final inclusion independently and in parallel by two reviewers, with any disagreements resolved by discussion with a third reviewer. When several versions of reviews were identified, only the most recent was included. If there was more than one publication of an identical review (e.g. a Cochrane review and a journal version including the same papers), the reference with the most detail was included.

\section{Data extraction and management}

The following data were extracted: bibliographic details (author, year, title); category (area of intervention); type of intervention; outcomes reported; number of included studies and/or participants; key findings; and authors' conclusions. Areas and types of intervention were not pre-defined, but emerged thematically and were rationalised during the screening process.

\section{Assessment of methodological quality of the systematic reviews}

Quality of included reviews was assessed using the AMSTAR2 tool, a 16-item measurement tool specifically used to assess systematic reviews that include randomised or non-randomised studies of healthcare interventions (or both) [13]. Five domains from the 16 items were considered to be "critical": 1) the adequacy of the literature search; 2) assessment of risk of bias in included studies; 3) appropriate meta-analytical methods; 4) consideration of risk of bias in interpreting the results of the review; and 5) assessment of presence and impact of publication (small study) bias. The other 10 domains were considered to be "non-critical". Confidence in the results of the review was classified as "high" if it had $<4$ non-critical and no critical weaknesses, "moderate" if $\geqslant 4$ non-critical but no critical weaknesses, "low" if one critical weakness, and "very low" if $\geqslant 2$ critical weaknesses [14]. Reviews of "risk factors" were not assessed for methodological quality.

\section{Data analysis}

Included reviews (direct or indirect effects) were summarised descriptively by category (area) of intervention, including the number and type of primary studies (randomised controlled trials (RCTs) or "other" studies, meaning non-randomised and observational studies). Areas of intervention were not specified a priori, but emerged by inspection of the topics covered by the included reviews, with the aim of defining areas which had the least amount of overlap. Reviews were categorised into either high-quality "core" reviews (high confidence in the results of the review according to AMSTAR2 criteria) which formed the basis of evidence used to assess interventions, or "supplementary" reviews which were not considered to be of sufficient quality to rely on the authors' conclusions but which provided additional information to complement the core reviews. For each type of intervention, we extracted information on the review authors' assessment of the evidence and the design and findings of primary studies included in that review. The overall level of evidence in support of, or discounting, the effectiveness of an intervention was classified as "sufficient", "tentative", "insufficient" or "no" review level evidence, using a framework based on the consistency of evidence within and between reviews, and concluding statements made by the authors (table 2).

\section{Results}

We identified 11578 references, including 1654 from MEDLINE, 2796 from EMBASE, 250 from CINAHL, 2949 from Scopus, 1059 from Global Health, 2040 from Trip, and 92 from Cochrane. Of these, 7499 were removed by de-duplication, leaving 4079 to be screened by title and abstract. Screening by title and 
TABLE 2 Framework to classify review level evidence

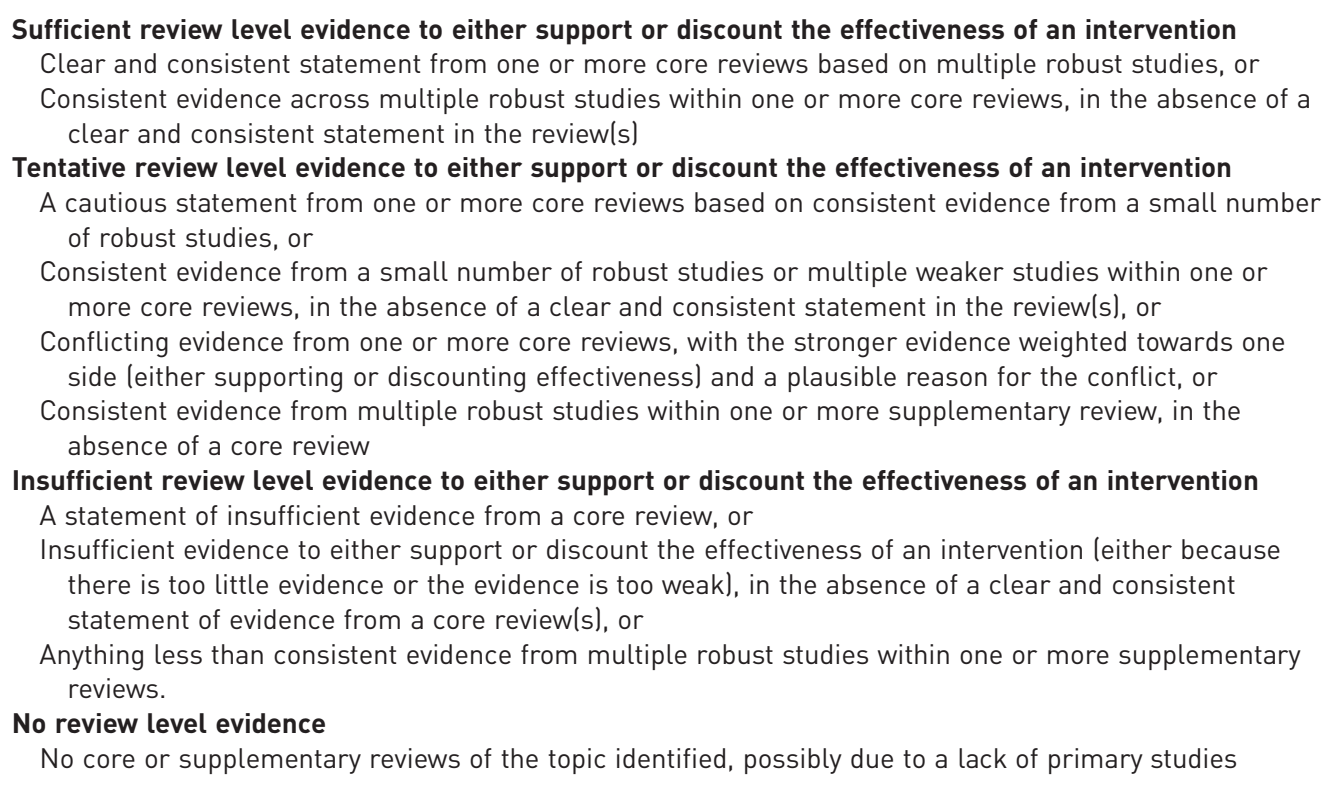

abstract eliminated 3813 references, leaving 266 references for full text review (figure 1). Of these, 187 were included, covering 13 areas of intervention (table 3) and comprising 45 reviews of interventions reporting a direct effect, 113 an indirect effect, and 29 describing risk or contextual factors (Appendix S3). Quality assessment rated direct effect (17 (37.8\%) out of 45$)$ and indirect effect (28 (24.8\%) out of 113 ) reviews as high-quality core reviews (table 4 and Appendix S4). A full textual data synthesis for each category of intervention stratified by effect is provided in Appendix S5. The results below summarise the overall (review level) evidence in support of, or discounting, the effectiveness of interventions.

\section{Sufficient review level evidence for direct or indirect effects of interventions Vaccination}

There was a sufficient level of evidence from systematic reviews to support the use of bacille CalmetteGuerin (BCG) vaccination, with evidence of protective effects against pulmonary and extrapulmonary $\mathrm{TB}$ of up to 10 years' duration. Vaccine efficacy varied by age and tuberculin sensitivity status at time of vaccination, and was greatest when comparing naïve individuals with naïve unvaccinated individuals. These results derived from four core reviews [15-18], the largest of which included 21 RCTs and 111 other studies, covering all age groups [15]. An update of this review, but restricted to neonatal and infant vaccination, found no additional studies [16]. These last two reviews recommended selective BCG vaccination, for example, of infants born to immigrants from high TB-incidence countries or close contacts of active TB cases, whilst acknowledging a lack of evidence for cost-effectiveness compared with universal vaccination.

\section{Diagnosis}

Diagnostic accuracy of TB diagnostic tests in different patient groups is increasingly well-characterised. There is insufficient review level evidence either to support or discount direct effects of interferon $\gamma$-release assays (IGRAs) compared with tuberculin skin test (TST) in predicting which cases of LTBI would progress to active $\mathrm{TB}$, i.e. the two tests are similar in predictive value (high negative predictive value, low positive predictive value). There is sufficient review level evidence of indirect effects on TB incidence of performing molecular drug susceptibility testing. This assessment was based on three core reviews of molecular drug susceptibility testing: 1) a UK HTA review of GenoType MTBDRplus (isoniazid (INH) and rifampicin), INNO-LiPA Rif.TB (rifampicin) and Xpert MTB/RIF (rifampicin) [51]; 2) a Cochrane review of the Xpert MTB/RIF assay [54]; and 3) a review of three commercial line probe assays, Hain Genotype MTBDRplusV1, MTBDRplusV2 and Nipro NTM+MDRTB [52]. The conclusion of all three reviews was that molecular tests had high sensitivity and specificity (regardless of HIV status) for rifampicin and INH resistance, e.g. for rifampicin resistance detection Xpert MTB/RIF pooled sensitivity and specificity were $95 \%$ and $98 \%$, respectively [54]. 

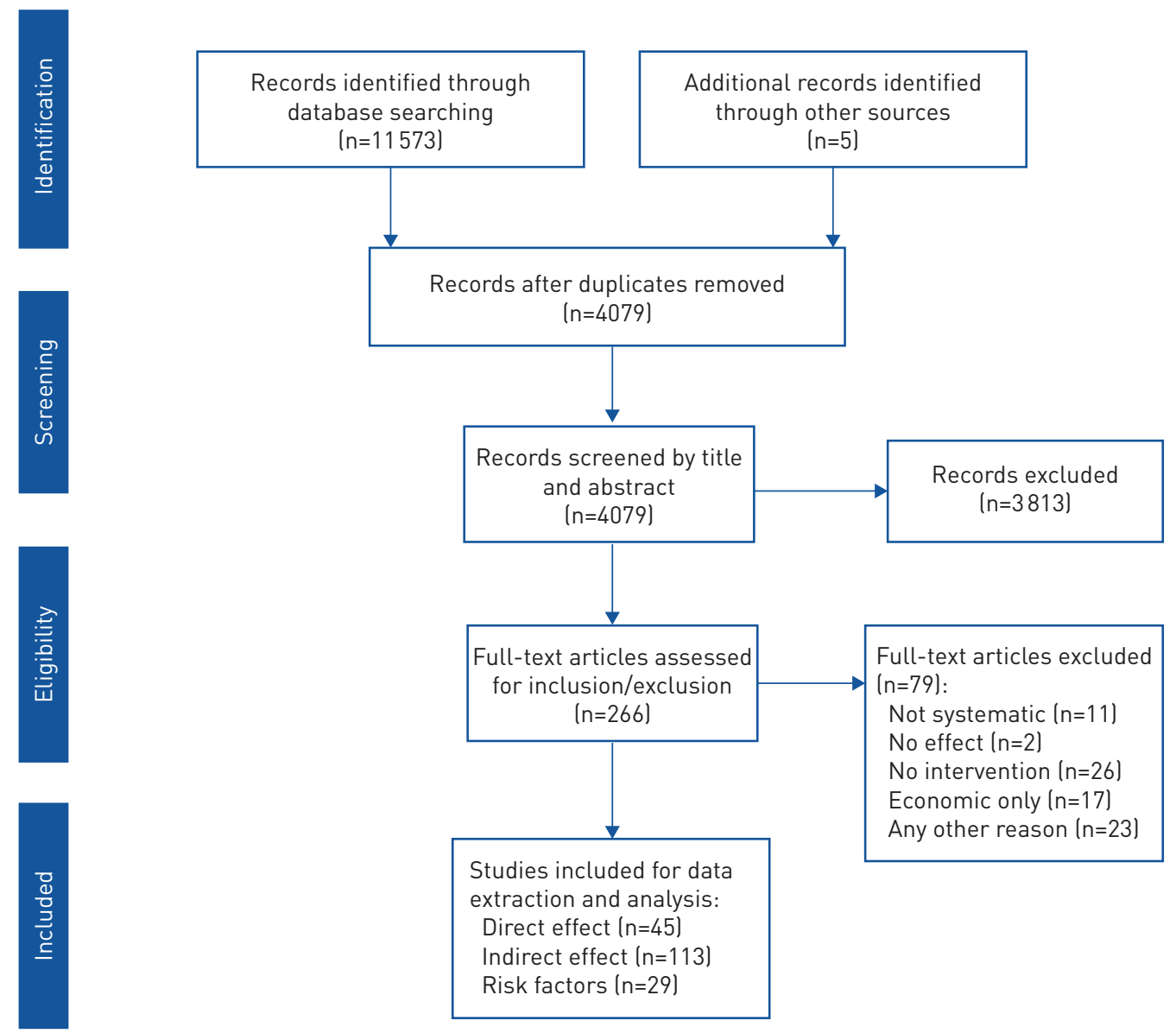

FIGURE 1 Study selection (PRISMA flow diagram).

Treatment

A sufficient level of evidence for the relative effectiveness of different drug regimens in treating LTBI to prevent progression to active TB was provided by four core reviews [63-66]. The largest and most recent was a network meta-analysis based on 61 RCTs covering all age groups, which found evidence for the efficacy and safety (compared to no treatment or placebo) of 6 months of INH monotherapy, 3-4 months of rifampicin monotherapy, and combination therapies with 3-4 months of INH and rifampicin, regardless of age and HIV status [66]. SHARMA et al. [64] (10 RCTs, all age groups) concluded that shortened regimens using rifampicin alone had not demonstrated higher rates of active TB when compared to longer INH regimens, probably with better treatment completion and fewer adverse events; and that shortened combined regimens of rifampicin with INH offered no advantage over longer INH regimens. The impact of LTBI treatment on TB incidence at population level has not been evaluated because its overall effectiveness is entirely dependent on related interventions, particularly screening.

There is sufficient review level evidence of indirect effects via sub-optimal outcomes related to treatment of INH-resistant TB with standardised regimens of first-line drugs, and three times weekly dosing throughout therapy and twice weekly dosing in the continuation phase compared with daily therapy. There is insufficient review level evidence for other treatment-related "interventions", including therapeutic drug monitoring, nutritional supplementation and smoking cessation. Whilst TB patients with diabetes appear to have worse outcomes, there is currently no evidence base for changes to TB treatment regimens.

\section{HIV/TB}

There is sufficient review level evidence to support LTBI treatment and antiretroviral therapy (ART) to prevent active TB in people infected with HIV, although this evidence derives mainly from studies in lowor middle-income countries. Of the three core reviews: one reviewed LTBI treatment in HIV-positive adults based on 12 RCTs, finding a reduced risk of active TB comparing various anti-TB drug regimens with placebo, particularly among patients with a positive TST [115]; another review in HIV-positive 
TABLE 3 Specific interventions evaluated by included reviews (not an exhaustive list)

\begin{tabular}{|c|c|}
\hline Intervention area & Specific interventions evaluated by included reviews \\
\hline Vaccination & BCG vaccination: universal or selective (contacts and high-risk groups) \\
\hline \multirow[t]{2}{*}{ Screening } & $\begin{array}{l}\text { Pre-, post- and point-of-arrival testing for active TB or LTBI in } \\
\text { migrants }\end{array}$ \\
\hline & $\begin{array}{l}\text { Active case finding in primary care settings, and in high-risk and } \\
\text { vulnerable population groups }\end{array}$ \\
\hline \multirow[t]{2}{*}{ Diagnosis } & Diagnostic accuracy of TST versus IGRA \\
\hline & Drug susceptibility testing \\
\hline \multirow[t]{4}{*}{ Treatment } & Efficacy and safety of drug regimens for treating LTBI \\
\hline & Therapeutic drug monitoring \\
\hline & Nutritional supplementation \\
\hline & Diabetes \\
\hline Adherence & $\begin{array}{l}\text { Directly observed treatment, incentives, lay healthcare workers and } \\
\text { reminder systems }\end{array}$ \\
\hline \multirow[t]{4}{*}{ HIV/TB } & $\begin{array}{l}\text { Efficacy and safety of antiretroviral therapy for treating HIV and/or } \\
\text { drug regimens for treating LTBI }\end{array}$ \\
\hline & Diagnostic accuracy of TST versus IGRA \\
\hline & Drug susceptibility testing \\
\hline & Service integration \\
\hline \multirow[t]{3}{*}{ MDR-TB } & Efficacy and safety of drug regimens for treating MDR-TB \\
\hline & $\begin{array}{l}\text { Efficacy and safety of drug regimens for preventing MDR-TB in } \\
\text { contacts of MDR-TB cases }\end{array}$ \\
\hline & Directly observed therapy and care models \\
\hline \multirow[t]{3}{*}{ Contacts and transmission } & Contact investigation \\
\hline & Whole genome sequencing \\
\hline & Air travel \\
\hline \multirow[t]{2}{*}{ Healthcare-associated infection } & Serial screening for TB in healthcare workers \\
\hline & Clinical prediction rules \\
\hline \multirow{2}{*}{$\begin{array}{l}\text { Social support and vulnerable } \\
\text { groups }\end{array}$} & Socioeconomic and psychosocial support \\
\hline & Reaching vulnerable groups \\
\hline \multirow[t]{3}{*}{ Healthcare systems } & Integrated care models \\
\hline & Scaling up \\
\hline & Task shifting \\
\hline \multirow[t]{2}{*}{ Pregnancy and sex } & $\begin{array}{l}\text { Efficacy and safety of drug regimens for treating active TB, LTBI and } \\
\text { MDR-TB }\end{array}$ \\
\hline & $\begin{array}{l}\text { Sex-specific approaches to TB diagnosis and treatment } \\
\text { Isoniazid preventive therapy }\end{array}$ \\
\hline Environment and behaviours & $\begin{array}{l}\text { Smoking, second-hand tobacco smoke and indoor air pollution } \\
\text { Alcohol }\end{array}$ \\
\hline
\end{tabular}

TB: tuberculosis; MDR-TB: multidrug-resistant TB; BCG: bacille Calmette-Guerin; LTBI: latent TB infection; TST: tuberculin skin test; IGRA: interferon $\gamma$-release assay.

children also reported a marked reduction in risk of active TB, but based on a single RCT [116]; and a review of ART for prevention of $\mathrm{TB}$ in adults based on three RCTs and eight other studies found a substantial reduction in TB incidence [117].

\section{Insufficient review level evidence for direct or indirect effects of interventions \\ Screening}

Whilst migrants from high TB incidence countries often have a higher prevalence of active and latent TB than the general population in low TB incidence countries, there was insufficient evidence from systematic reviews to either support or discount the effectiveness of different screening approaches to prevent TB cases, reducing TB incidence, reducing mortality or preventing transmission. Eight supplementary reviews of migrant screening (two reviewing pre-entry screening/follow-up [32, 34], one point-of-entry screening [42], four post-entry screening [33, 36-38] and one screening at all three points [45]) favoured pre- or post-entry screening of migrants from high TB-incidence countries (based mainly on case yield and risk of TB developing post-entry) compared with no screening, but none compared the effectiveness of different approaches or provided conclusive evidence of cost-effectiveness. All eight reviews stressed the need for comparative studies and improved longitudinal data collection. 
TABLE 4 Studies included and excluded after full text review

Included reviews

Excluded

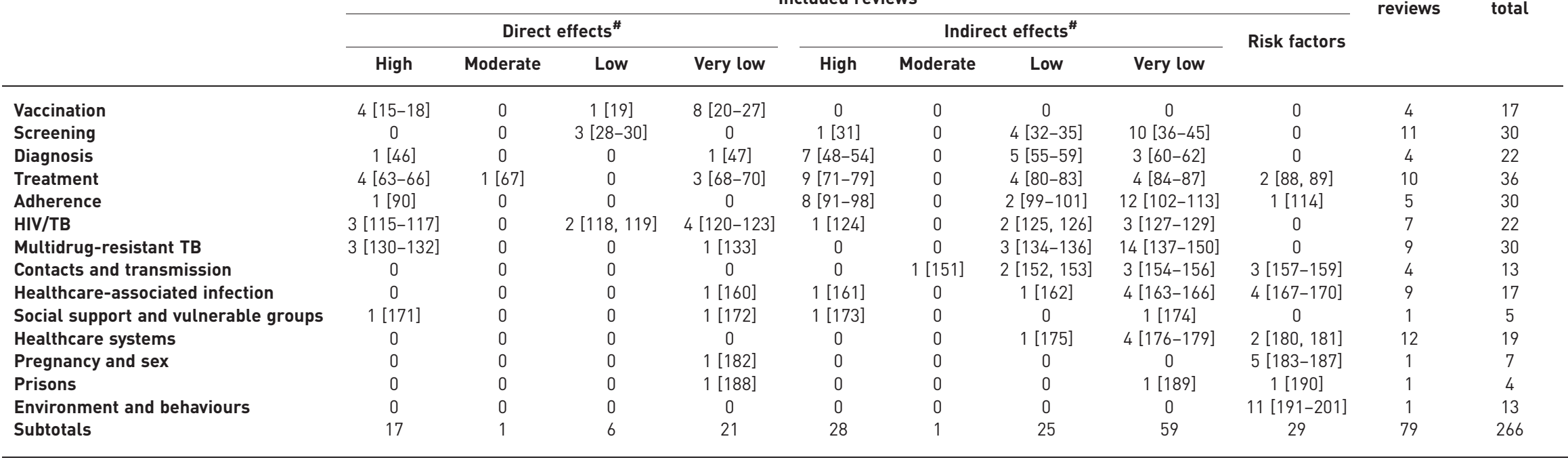

Direct effect: evidence that intervention has a direct effect in preventing cases or reducing incidence, reported as a primary or secondary outcome measure of the review; indirect effect: intervention has a plausible indirect effect in preventing tuberculosis (TB) cases or reducing TB incidence, regardless of the outcome measures reported in the review; risk factors: no intervention was evaluated but the review described risk (or contextual) factors which could modify the effects of interventions or which, if targeted in a hypothetical intervention, could lead to a reduction in TB incidence. " : the AMSTAR2 criteria were used to categorise the included reviews as either "core" reviews (providing an evidence base for interventions) of high quality or "supplementary" reviews (providing additional information) of moderate, low or very low quality. 


\section{Adherence}

There is insufficient review level evidence, particularly in high-income/low TB-incidence countries, to support or discount direct or indirect effects of treatment adherence interventions to reduce the incidence of active TB, including directly observed treatment (DOT), incentives, lay healthcare workers (HCWs) or reminder systems. Interventions to improve TB treatment adherence must address a host of complex and interacting barriers and facilitators. This assessment was based on nine core reviews, one relating to direct effects [90] and eight relating to indirect effects [91-98]. M'Imunya et al. [90] reviewed studies of patient education and counselling for promoting adherence to TB treatment, finding three trials which reported LTBI treatment completion rates (children in Spain, adolescents in the USA, and prisoners in the USA). Although incidence of active TB was a stated outcome of the review, no studies were identified which measured progression to active TB. There were two core reviews of DOT [91, 97]. The Cochrane review authors [91] concluded that there was insufficient evidence overall to either support or discount the effectiveness of DOT in terms of TB treatment completion or cure, although only two out of 11 included studies were set in high-income countries (USA and Australia). A core review of incentive-based approaches [94] which included 10 studies from the USA (out of 12 included studies) found that material incentives and enablers had: little or no effect in improving the outcomes of patients on treatment for active TB; some effects on completion of prophylaxis for latent TB in some circumstances (but trial results were mixed); and some positive short-term effects on clinic attendance for diagnostic test results and prophylaxis, particularly for marginal populations such as drug users, recently released prisoners and the homeless, but insufficient evidence to know if they can improve long-term adherence to TB treatment.

\section{MDR-TB}

Pooled analysis indicates overall treatment success rates of $26 \%$ and $60 \%$ for extensively drug-resistant (XDR)- and MDR-TB patients, respectively [139]. No core reviews were found in relation to approaches to MDR-TB treatment (e.g. drug regimens). Some of the supplementary reviews of drug regimens made specific recommendations, e.g. linezolid for the treatment of XDR-TB or fluoroquinolone-resistant MDR-TB [135] and six- and four-drug combinations in the intensive and continuation phases of XDR-TB treatment [141], but the common conclusion was the urgent need for more RCTs of MDR- and XDR-TB treatments. Three core reviews were identified in relation to preventive treatments for contacts of MDR-TB cases, two of which found no evidence of effectiveness [130, 132]; a third was focused on adverse events, finding no evidence of these [131]. Overall, there is insufficient review level evidence for effects of interventions on MDR-TB incidence in MDR-TB cases or contacts.

\section{Contacts and transmission}

No core reviews were identified, and there is insufficient review level evidence from supplementary reviews for specific interventions to improve contact investigation, in terms of direct or indirect effects on TB incidence. The supplementary reviews recommend pragmatic actions such as investigating contacts of MDR-TB cases, and LTBI treatment for child or HIV-positive contacts of active TB cases [152, 154-156], or describing potential benefits of whole genome sequencing to support epidemiological investigations [151, 153]. Two reviews of TB in relation to air travel indicated a low risk of transmission in airplanes [157, 159].

\section{Healthcare-associated infection}

There is insufficient review level evidence for TB-specific interventions for HCWs or infection control in healthcare settings, although this reflects a lack of systematic reviews in this area particularly in high-income countries. There were three supplementary reviews on TB screening in HCWs [164-166]. LAMBERTI et al. [164] concluded that, in the absence of a gold-standard test, TB surveillance in HCWs needed to consider factors such as vaccination status, age and role, whilst ZwERLING et al. [166] commented that use of IGRAs for serial testing in HCWs is complicated by lack of data on optimum cut-offs. Two supplementary reviews analysed clinical prediction rules for respiratory isolation of patients with presumptive pulmonary TB [162, 163], both reviews indicated that clinical prediction rules tend to have high sensitivity but low specificity, with inconclusive evidence for their utility in low TB-incidence settings.

\section{Social support and vulnerable groups}

There is insufficient review level evidence to support or discount the effectiveness of TB-specific social support interventions or interventions in vulnerable groups. One core review by HeuveLINGs et al. [171] was identified, which reviewed a wide range of interventions for diagnosis and treatment of $\mathrm{TB}$ in hard-to-reach populations. This review extended and updated two earlier reviews by the UK National Institute for Health and Care Excellence (NICE) [202, 203]. Of the 44 included primary studies, three had reduction of $\mathrm{TB}$ incidence or number of $\mathrm{TB}$ cases prevented as outcomes; two of these studies were included in other systematic reviews that we have reviewed under "screening". The remaining study was a non-randomised study of a social and healthcare programme for homeless people in Spain which reported 
pre-/post-intervention TB incidence compared with a non-intervention area as an outcome, but no reliable conclusion could be drawn regarding the programme's effectiveness [204]. A core review of psychosocial and socioeconomic support found that these appeared to improve treatment outcomes across a variety of settings and patient populations, but the authors rated the quality of the primary studies as very low [173].

\section{Healthcare systems}

There is insufficient review level evidence to support or discount the effectiveness of TB-specific interventions at the level of healthcare systems in high-/low-incidence countries. Four of the five supplementary reviews focused mainly on healthcare system interventions in low and middle-income countries, including mixed public-private approaches [177], task-shifting (e.g. of treatment supervision to community health workers, laypersons or family [178]), scaling-up of TB interventions such as isoniazid preventive therapy, clinical algorithms and second-line treatment [176], and best practice in evaluating specialist HCW training [179]. The fifth supplementary review comprised six separate reviews commissioned to inform UK NICE guidelines for TB [175], including a review of information and education interventions for service providers which concluded that intensive interventions integrating clinician education with other components such as reminders, process improvement and incentives could be effective in improving service delivery outcomes, particularly TB screening.

\section{Pregnancy}

There is insufficient review level evidence for direct or indirect effects of specific interventions relating to TB during pregnancy. One supplementary review of 35 non-randomised studies included two which investigated treatment of LTBI with INH during pregnancy (neither reported progression to active TB as an outcome), 14 reported treatment of active TB and four reported treatment of MDR-TB [182]. The authors highlighted delays in diagnosing and treating TB during pregnancy, poor adherence to INH preventive therapy (and a possible elevated risk of INH toxic hepatitis), but the reviewed studies showed no association between child abnormality and mother's exposure to first- or second-line anti-TB drugs.

\section{Prisons}

TB incidence is often higher in correctional facilities than in the general population, but beyond standard TB diagnosis and treatment procedures and infection control measures, there is insufficient review level evidence for specific interventions in the context of prisons. One supplementary review of studies of INH preventive therapy in prisons identified four studies which reported TB incidence as an outcome [188]. The review was of very low quality, and no conclusion could be drawn regarding the effectiveness of LTBI treatment regimens in prison settings. A supplementary review identified limited accuracy of diagnostic algorithms and lack of adequate laboratory facilities as key limitations for TB control programmes in prisons [189].

\section{Environment and behaviours}

Whilst plausible associations of smoking and heavy alcohol consumption and, to a lesser extent, second-hand tobacco smoke and indoor air pollution with TB were supported by a number of reviews [191-201], there is as yet no review level evidence to support either the incorporation of smoking- or alcohol-related interventions into programmes for $\mathrm{TB}$ control and prevention or to address these factors in relation to treatment outcomes.

\section{Discussion}

Our review focused on interventions for which reduction in TB incidence and prevention of TB cases was a directly measurable outcome, or could be inferred indirectly from another reported outcome, based on evidence from systematic reviews. Clearly, we recognise the basic obligation to provide TB patients with high-quality evidence-based clinical care that reduces suffering and mortality, and to make this standard of care accessible to everyone. From this point of departure, our review identified two interventions supported by sufficient review level evidence of direct effects in reducing TB incidence and preventing TB cases, namely BCG vaccination and treatment of LTBI to prevent progression to active TB.

The insufficient review level evidence of direct effects in other intervention areas is a consequence of two related factors: 1) the lack of good quality primary studies; and 2) the lack of good quality systematic reviews. The first of these may be because policymakers perceive no added value in testing interventions which, by simple logic, should have a beneficial impact (or where effectiveness, e.g. of drug regimens for uncomplicated TB, is not disputed). Such testing may be unethical or would require RCTs of complex interventions at large enough scale and of sufficient duration to detect an effect on TB incidence. The second factor follows from the first or, where experimental evidence is available, reflects the difficulty of synthesising evidence with substantial heterogeneity in settings, interventions and outcomes. In the 
absence of a comprehensive, consistent and robust review level evidence base, the choice of interventions for TB control plans and programmes will continue to be pragmatic, at best supported by evidence from individual studies, but otherwise based on local TB epidemiology, expert opinion and accumulated national and international experience.

One of the main challenges to building an evidence base in TB control and prevention at national level is the interconnectedness of interventions along the "cascade of care" from detection of TB through to successful completion of treatment [181]. This implies that interventions need to be evaluated in a joined-up rather than standalone manner. Also, the biggest impact on TB incidence over time has come from societal, socioeconomic and wider healthcare improvements, which are beyond the remit of a TB control plan. These changing factors, together with non-static populations, preclude before-and-after studies as an unbiased method for evaluating TB-specific interventions [205]. Without substantial investment to strengthen the evidence base, the pragmatic alternative is to accept that "good" interventions may not be supported by "hard" evidence, and to trust that implementing a range of common-sense interventions, alongside population-level improvements in social determinants and risk factors and continual improvements in the effectiveness and quality of clinical care, will eventually lead to elimination of TB. A persuasive counter-argument can be made that interventions deemed to be "good" even by the application of logic may not be as effective as thought, or could be made more effective, hence why more investment in research is essential. This research may require methodological innovation, such as using a factorial trial design to add interventions, e.g. screening and reminder systems, to an optimised programme of diagnosis and treatment, and measuring transmission (using molecular methods) as an outcome [206].

\section{Our findings in context \\ Vaccination}

We reported sufficient evidence of protection against TB by BCG vaccination from four reviews. These indicate that an important role remains for vaccination targeted at high-risk groups who are most likely to benefit because of higher risk of exposure, with recent research suggesting $>15$ years' duration of protection by BCG $[207,208]$. Although RCT evidence for the use of BCG in high-risk groups is unlikely to be forthcoming for ethical reasons, TB control programmes should probably adopt this approach whilst the search for a new and more effective TB vaccine continues [209].

\section{Diagnosis and treatment}

Perhaps unsurprisingly, these two areas accounted for the highest number of high-quality core reviews (21 out of 45 core reviews in total; eight in diagnostics, 13 in treatment). This reflects the relative ease with which comparative clinical studies of diagnostic methods and treatment regimens can be designed, conducted and systematically reviewed, compared with evaluations of complex interventions. Clinical studies tend to capture outcomes such as treatment success and diagnostic accuracy, hence the majority were categorised as having indirect effects on TB incidence that were not quantified as an outcome of the included systematic review. Translating outcomes such as treatment efficacy into effects on TB incidence is an area where modelling can be of some use [210]. That we found review level evidence for direct effects on TB incidence of LTBI treatment and indirect effects of DST and sub-optimal treatment highlights the importance of continuing to build a high-quality evidence base to support best practice in clinical care, and of continuing to develop more accurate diagnostic tests and more efficacious and safer drugs.

\section{Screening and LTBI}

We found that evidence for the efficacy of LTBI treatment in contacts and persons with certain comorbidities is robust, whilst evidence for LTBI screening, especially population-based programmes, is much weaker. This lack of evidence is particularly important in view of south-north migration [211-214]. The recent push towards TB elimination in low-incidence countries in keeping with the ambitious End TB Strategy has increased interest in systematic LTBI screening and treatment, because most TB disease in these countries is a result of LTBI reactivation. It is worth noting that WHO issued strong recommendations for LTBI treatment of persons with certain comorbidities, such as underlying immunosuppressive diseases or medications, whilst only issuing conditional recommendations for wider screening of migrants from high-incidence countries [215]. The trade-off and tension between provision of LTBI treatment to only a few high-risk patients who have high likelihood of individual benefit from treatment, but with little or no effect on country-level incidence, versus provision of screening to a larger group at lower risk (such as migrants) with lower expected individual benefit but higher likelihood of reducing population-level incidence, remains unresolved. Ultimately, national TB strategic planning must base decisions about screening programmes on context, cost considerations and local TB epidemiology, including the rate of MDR TB, for which LTBI treatment is still in its infancy. 


\section{Adherence}

Many variants on interventions to improve treatment adherence have been evaluated, particularly in higher TB burden settings. Recent WHO guidelines [216] recommend that treatment should be based on an assessment of individual patients' needs, providers' resources and conditions for implementation. The paucity of review level evidence for direct effects on reducing the incidence of active TB in low-incidence countries suggests the need for evaluation studies that can account for the complex and intersecting determinants of poor adherence, which can vary both within an individual and over the course of treatment. Under the auspices of the End TB Strategy there is a need to intensify efforts to design and test public health interventions that explicitly target modifiable social and behavioural determinants of adherence, thereby supporting high-risk groups in accessing and engaging with patient-centred care.

\section{Strengths and limitations}

The main strength of our study is the consistent methodology applied to all reviewed systematic reviews, covering a wide range of interventions. We applied rigorous quality assessment criteria, the results of which are consistent with an earlier assessment of the quality of systematic reviews on TB [217]. The main limitation of a "review of reviews" approach is that evidence from primary studies will not be assessed if those studies have not been systematically reviewed. Where studies have been reviewed, some "detail" may be lost because we are synthesising evidence which has already been synthesised. We did report some pertinent details from individual studies included in systematic reviews, where these primary studies provided the only evidence for a particular intervention, but unreplicated single-study evidence must be interpreted with caution. It has also been argued that systematic reviews may fail to capture effects of complex interventions, such as DOT, particularly where simplified outcome measures are used [218]. This is an area where qualitative systematic reviews could potentially contribute to evidence of effectiveness. Where we found sufficient evidence for effects of interventions on TB incidence, we did not attempt to quantify the magnitude of these effects. For example, BCG vaccination of infants in high-risk groups will have little impact on overall TB incidence and case numbers in low-incidence countries because children represent a small proportion of TB cases. As a public health intervention in low-incidence countries, BCG will be more effective in preventing life-threatening paediatric TB cases, e.g. meningitis, than in reducing overall TB incidence.

\section{Implications of our findings for TB control plans and strategies}

The objective of our review was to synthesise an evidence base for the effectiveness of interventions for TB control and prevention in low-incidence settings. Our aim was to use this evidence to inform the development of a TB Strategy Toolkit for EU/EEA countries, which will include guidance on the prioritisation of interventions within national TB control plans. The toolkit will be developed through a consensus approach, incorporating other types of evidence including a survey of current practices and priorities in EU/EEA countries [6], qualitative reviews of barriers and enablers to TB control [219, 220], current international standards, and WHO and ECDC guidelines [221]. This consensus process will address questions such as how to link national TB plans, which need to focus on strategic choices around interventions to reduce the overall burden of TB in the population, with continually evolving guidelines and evidence around best practice in TB patient care. Our review has shown the need for more evidence to support expert opinion and to support local experience when making policy decisions in TB control and prevention.

Acknowledgements: We would like to thank Anh Tran at Public Health England Knowledge and Library Services (London, UK) for her assistance with this review.

Author contributions: D. Zenner conceptualised the initial hypothesis and idea for the study and provided overall supervision. S.M. Collin performed the database searches. S.M. Collin and M.C. Muzyamba screened references. S.M. Collin assessed study quality and extracted data. S.M. Collin and F. Wurie summarised and synthesised the data. S.M. Collin and D. Zenner drafted the paper with input from G. de Vries, K. Lönnroth, G.B. Migliori, I. Abubakar and S.R. Anderson. S.M. Collin had full access to all the data in the study and takes responsibility for the integrity of the data and the accuracy of the data analysis. All authors contributed to drafting the manuscript and reviewing it for important intellectual content. All authors approved the final manuscript.

Conflict of interest: None declared.

Support statement: This study is part of the E-DETECT TB project (ref. 709624) which has received funding from the European Union's Health Programme (2014-2020). The content of this paper represents the views of the authors only and is their joint responsibility; it cannot be considered to reflect the views of the European Commission and/or the Consumers, Health, Agriculture and Food Executive Agency or any other body of the European Union. The European Commission and the Agency do not accept any responsibility for use that may be made of the information it contains. The study is within the remit of the research activities of the WHO Collaborating Centre for TB and Lung Diseases, Fondazione S. Maugeri, Tradate, Italy and of the Global Tuberculosis Network. Funding information for this article has been deposited with the Crossref Funder Registry. 


\section{References}

1 Centis R, D’Ambrosio L, Zumla A, et al. Shifting from tuberculosis control to elimination: Where are we? What are the variables and limitations? Is it achievable? Int J Infect Dis 2017; 56: 30-33.

2 Lonnroth K, Migliori GB, Abubakar I, et al. Towards tuberculosis elimination: an action framework for low-incidence countries. Eur Respir J 2015; 45: 928-952.

3 van Hest NA, Aldridge RW, de Vries G, et al. Tuberculosis control in big cities and urban risk groups in the European Union: a consensus statement. Euro Surveill 2014; 19: 20728.

4 Kunst H, Burman M, Arnesen TM, et al. Tuberculosis and latent tuberculous infection screening of migrants in Europe: comparative analysis of policies, surveillance systems and results. Int J Tuberc Lung Dis 2017; 21: 840-851. ECDC/WHO Regional Office for Europe. Tuberculosis surveillance and monitoring in Europe 2018. Stockholm, ECDC, 2018.

6 Collin SM, de Vries G, Lonnroth K, et al. Tuberculosis in the European Union and European Economic Area: a survey of national tuberculosis programmes. Eur Respir J 2018; 52: 1801449.

$7 \quad$ Higgins JP, Green S, eds. Cochrane Handbook for Systematic Reviews of Interventions Version 5.1.0 [updated March 2011]. The Cochrane Collaboration, 2011.

8 Li T, Vedula SS, Scherer R, et al. What comparative effectiveness research is needed? A framework for using guidelines and systematic reviews to identify evidence gaps and research priorities. Ann Intern Med 2012; 156: 367-377.

9 E-DETECT TB. 2017. Early Detection and Integrated Management of Tuberculosis in Europe (E-DETECT TB) www.e-detecttb.eu.

10 Abubakar I, Matteelli A, de Vries G, et al. Towards tackling tuberculosis in vulnerable groups in the European Union: the E-DETECT TB consortium. Eur Respir J 2018; 51: 1702604.

11 World Health Organization. Global tuberculosis report 2018. Geneva, World Health Organization, 2018.

12 Lee E, Dobbins M, Decorby K, et al. An optimal search filter for retrieving systematic reviews and meta-analyses BMC Med Res Methodol 2012; 12: 51.

13 Shea BJ, Reeves BC, Wells G, et al. AMSTAR 2: a critical appraisal tool for systematic reviews that include randomised or non-randomised studies of healthcare interventions, or both. BMJ 2017; 358: j4008.

14 MacArthur GJ, van Velzen E, Palmateer N, et al. Interventions to prevent HIV and hepatitis C in people who inject drugs: a review of reviews to assess evidence of effectiveness. Int J Drug Policy 2014; 25: 34-52.

15 Abubakar I, Pimpin L, Ariti C, et al. Systematic review and meta-analysis of the current evidence on the duration of protection by bacillus Calmette-Guerin vaccination against tuberculosis. Health Technol Assess 2013; 17: $1-372$.

16 Health Information and Quality Authority. Health technology assessment of a selective BCG vaccination programme. Geneva, Health Information and Quality Authority, 2015.

17 Mangtani P, Abubakar I, Ariti C, et al. Protection by BCG vaccine against tuberculosis: a systematic review of randomized controlled trials. Clin Infect Dis 2014; 58: 470-480.

18 Roy A, Eisenhut M, Harris RJ, et al. Effect of BCG vaccination against Mycobacterium tuberculosis infection in children: systematic review and meta-analysis. BMJ 2014; 349: g4643.

19 Ortqvist A, Blennow M, Carlsson RM, et al. Vaccination of children - a systematic review. Acta Paediatr 2010; 99: 1-192.

20 Brewer TF. Preventing tuberculosis with bacillus Calmette-Guerin vaccine: a meta-analysis of the literature. Clin Infect Dis 2000; 31: Suppl. 3, S64-S67.

21 Colditz GA, Berkey CS, Mosteller F, et al. The efficacy of bacillus Calmette-Guerin vaccination of newborns and infants in the prevention of tuberculosis: meta-analyses of the published literature. Pediatrics 1995; 96: 29-35.

22 Knuf M, Habermehl P, Schuind A, et al. Efficacy of BCG vaccination. Monatsschr Kinderheilkd 1996; 144: 648-654.

23 Schmitz S, Usher C, Adams R, et al. Meta-analysis of BCG vaccine efficacy for infants in Ireland. Value Health 2013; 16: A331.

24 Steffen R, Behrens RH, Hill DR, et al. Vaccine-preventable travel health risks: what is the evidence - what are the gaps? J Travel Med 2015; 22: 1-12.

25 Sterne JAC, Rodrigues LC, Guedes IN. Does the efficacy of BCG decline with time since vaccination? Int J Tuberc Lung Dis 1998; 2: 200-207.

26 Tamuzi JL, Muyaya LM, Tshimwanga JL. Co-administration of oral polio vaccine and Bacillus Calmette-Guerin in infants: systematic review of low- and middle-income countries. Int Ann Med 2017; 11: 1.

27 Thomas RE. Preparing patients to travel abroad safely. Part 2: updating vaccinations. Can Fam Physician 2000; 46: 646-652.

28 Curtis J. Impact of $\mathrm{x}$-ray screening programmes for active tuberculosis in homeless populations: a systematic review of original studies. J Public Health (Oxf) 2016; 38: 106-114.

29 Paquette K, Cheng MP, Kadatz MJ, et al. Chest radiography for active tuberculosis case finding in the homeless: a systematic review and meta-analysis. Int J Tuberc Lung Dis 2014; 18: 1231-1236.

30 Kahwati LC, Feltner C, Halpern M, et al. Primary care screening and treatment for latent tuberculosis infection in adults: evidence report and systematic review for the US Preventive Services Task Force. JAMA 2016; 316: 970-983.

31 van't Hoog AH, Langendam MW, Mitchell E, et al. A systematic review of the sensitivity and specificity of symptom- and chest-radiography screening for active pulmonary tuberculosis in HIV-negative persons and persons with unknown HIV status. Geneva, World Health Organisation, 2013.

32 Aldridge RW, Yates TA, Zenner D, et al. Pre-entry screening programmes for tuberculosis in migrants to low-incidence countries: a systematic review and meta-analysis. Lancet Infect Dis 2014; 14: 1240-1249.

33 Campbell JR, Krot J, Elwood K, et al. A systematic review on TST and IGRA tests used for diagnosis of LTBI in immigrants. Mol Diagn Ther 2015; 19: 9-24.

34 Chan IHY, Kaushik N, Dobler CC. Post-migration follow-up of migrants identified to be at increased risk of developing tuberculosis at pre-migration screening: a systematic review and meta-analysis. Lancet Infect Dis 2017; 17: 770-779. 
Kranzer $\mathrm{K}$, Afnan-Holmes $\mathrm{H}$, Tomlin $\mathrm{K}$, et al. The benefits to communities and individuals of screening for active tuberculosis disease: a systematic review. Int J Tuberc Lung Dis 2013; 17: 432-446.

Arshad S, Bavan L, Gajari K, et al. Active screening at entry for tuberculosis among new immigrants: a systematic review and meta-analysis. Eur Respir J 2010; 35: 1336-1345.

Bozorgmehr K, Razum O, Saure D, et al. Yield of active screening for tuberculosis among asylum seekers in Germany: a systematic review and meta-analysis. Euro Surveill 2017; 22: 30491.

Campbell JR, Chen W, Johnston J, et al. Latent tuberculosis infection screening in immigrants to low-incidence countries: a meta-analysis. Mol Diagn Ther 2015; 19: 107-117.

Greveson K. Can ELISpot replace the tuberculin skin test for latent tuberculosis? Br J Nurs 2009; 18: 1248-1254.

Jeon CY, Harries AD, Baker MA, et al. Bi-directional screening for tuberculosis and diabetes: a systematic review. Trop Med Int Health 2010; 15: 1300-1314.

Malekinejad M, Parriott A, Viitanen AP, et al. Yield of community-based tuberculosis targeted testing and treatment in foreign-born populations in the United States: a systematic review. PLoS One 2017; 12: e0180707.

Sammeh A, Alsharif M. Effectiveness and cost effectiveness of screening immigrants schemes for tuberculosis (TB) on arrival from high TB endemic countries to low TB prevalent countries. Afr Health Sci 2014; 14: 663-671.

Shapiro AE, Chakravorty R, Akande T, et al. A systematic review of the number needed to screen to detect a case of active tuberculosis in different risk groups. Geneva, World Health Organisation, 2013.

Tan L, Altman RD, Nielsen NH, et al. Screening nonimmigrant visitors to the United States for tuberculosis: report of the Council on Scientific Affairs. Arch Intern Med 2001; 161: 334-340.

Zenner D, Hafezi H, Potter J, et al. Effectiveness and cost-effectiveness of screening migrants for active tuberculosis and latent tuberculous infection. Int J Tuberc Lung Dis 2017; 21: 965-976.

Auguste P, Tsertsvadze A, Pink J, et al. Comparing interferon-gamma release assays with tuberculin skin test for identifying latent tuberculosis infection that progresses to active tuberculosis: systematic review and meta-analysis. BMC Infect Dis 2017; 17: 200.

Munoz L, Santin M. Interferon-gamma release assays versus tuberculin skin test for targeting people for tuberculosis preventive treatment: an evidence-based review. J Infect 2013; 66: 381-387.

Auguste P, Tsertsvadze A, Pink J, et al. Accurate diagnosis of latent tuberculosis in children, people who are immunocompromised or at risk from immunosuppression and recent arrivals from countries with a high incidence of tuberculosis: systematic review and economic evaluation. Health Technol Assess 2016; 20: 1-678.

Ayubi E, Doosti-Irani A, Mostafavi E. Do the tuberculin skin test and the QuantiFERON-TB Gold in-tube test agree in detecting latent tuberculosis among high-risk contacts? A systematic review and meta-analysis. Epidemiol Health 2015; 37: e2015043.

Dinnes J, Deeks J, Kunst H, et al. A systematic review of rapid diagnostic tests for the detection of tuberculosis infection. Health Technol Assess 2007; 11: 1-196.

Drobniewski F, Cooke M, Jordan J, et al. Systematic review, meta-analysis and economic modelling of molecular diagnostic tests for antibiotic resistance in tuberculosis. Health Technol Assess 2015; 19: 1-188.

Nathavitharana RR, Cudahy PG, Schumacher SG, et al. Accuracy of line probe assays for the diagnosis of pulmonary and multidrug-resistant tuberculosis: a systematic review and meta-analysis. Eur Respir J 2017; 49: 1601075.

Pinto LM, Dheda K, Schwartzman K, et al. Scoring systems using chest radiographic features for the diagnosis of pulmonary tuberculosis in adults: a systematic review. Eur Respir J 2013; 42: 480-494.

Steingart KR, Schiller I, Horne DJ, et al. Xpert(R) MTB/RIF assay for pulmonary tuberculosis and rifampicin resistance in adults. Cochrane Database Syst Rev 2014: CD009593.

Chang KC, Leung CC. Systematic review of interferon-gamma release assays in tuberculosis: focus on likelihood ratios. Thorax 2010; 65: 271-276.

Diel R, Loddenkemper R, Nienhaus A. Predictive value of interferon-gamma release assays and tuberculin skin testing for progression from latent TB infection to disease state: a meta-analysis. Chest 2012; 142: 63-75.

Horne DJ, Pinto LM, Arentz M, et al. Diagnostic accuracy and reproducibility of WHO-endorsed phenotypic drug susceptibility testing methods for first-line and second-line antituberculosis drugs. J Clin Microbiol 2013; 51: 393-401.

Martin A, Panaiotov S, Portaels F, et al. The nitrate reductase assay for the rapid detection of isoniazid and rifampicin resistance in Mycobacterium tuberculosis: a systematic review and meta-analysis. J Antimicrob Chemother 2008; 62: 56-64.

Martin A, Portaels F, Palomino JC. Colorimetric redox-indicator methods for the rapid detection of multidrug resistance in Mycobacterium tuberculosis: a systematic review and meta-analysis. J Antimicrob Chemother 2007; 59: 175-183.

Mase SR, Ramsay A, Ng V, et al. Yield of serial sputum specimen examinations in the diagnosis of pulmonary tuberculosis: a systematic review. Int J Tuberc Lung Dis 2007; 11: 485-495.

Minion J, Leung E, Menzies D, et al. Microscopic-observation drug susceptibility and thin layer agar assays for the detection of drug resistant tuberculosis: a systematic review and meta-analysis. Lancet Infect Dis 2010; 10: 688-698.

2 Morgan M, Kalantri S, Flores L, et al. A commercial line probe assay for the rapid detection of rifampicin resistance in Mycobacterium tuberculosis: a systematic review and meta-analysis. BMC Infect Dis 2005; 5: 62.

Ena J, Valls V. Short-course therapy with rifampin plus isoniazid, compared with standard therapy with isoniazid, for latent tuberculosis infection: a meta-analysis. Clin Infect Dis 2005; 40: 670-676.

Sharma SK, Sharma A, Kadhiravan T, et al. Rifamycins (rifampicin, rifabutin and rifapentine) compared to isoniazid for preventing tuberculosis in HIV-negative people at risk of active TB. Cochrane Database Syst Rev 2013; 7: CD007545.

5 Smieja MJ, Marchetti CA, Cook DJ, et al. Isoniazid for preventing tuberculosis in non-HIV infected persons. Cochrane Database Syst Rev 2000: 2: CD001363.

Zenner D, Beer N, Harris RJ, et al. Treatment of latent tuberculosis infection: an updated network meta-analysis. Ann Intern Med 2017; 167: 248-255.

Balcells ME, Thomas SL, Godfrey-Faussett P, et al. Isoniazid preventive therapy and risk for resistant tuberculosis. Emerging Infect Dis 2006; 12: 744-751. 

latent tuberculosis. Eur Respir J 2013; 42: Suppl. 57, 3533.

69 Cox HS, Morrow M, Deutschmann PW. Long term efficacy of DOTS regimens for tuberculosis: systematic review. BMJ 2008; 336: 484-487.

70 Haas MK, Belknap RW. A review of rifapentine for treating active and latent tuberculosis. Clin Investig (Lond) 2015; 5: 829-838.

71 Gallardo CR, Rigau Comas D, Valderrama Rodriguez A, et al. Fixed-dose combinations of drugs versus single-drug formulations for treating pulmonary tuberculosis. Cochrane Database Syst Rev 2016; 5: CD009913.

72 Gegia M, Winters N, Benedetti A, et al. Treatment of isoniazid-resistant tuberculosis with first-line drugs: a systematic review and meta-analysis. Lancet Infect Dis 2017; 17: 223-234.

73 Grobler L, Nagpal S, Sudarsanam TD, et al. Nutritional supplements for people being treated for active tuberculosis. Cochrane Database Syst Rev 2016; 6: CD006086.

74 Jeyashree K, Kathirvel S, Shewade HD, et al. Smoking cessation interventions for pulmonary tuberculosis treatment outcomes. Cochrane Database Syst Rev 2016; 1: CD011125.

75 Johnston JC, Campbell JR, Menzies D. Effect of intermittency on treatment outcomes in pulmonary tuberculosis: an updated systematic review and meta-analysis. Clin Infect Dis 2017; 64: 1211-1220.

76 Kasozi S, Clark J, Doi SA. Intermittent versus daily pulmonary tuberculosis treatment regimens: a meta-analysis. Clin Med Res 2015; 13: 117-138.

77 Menzies D, Benedetti A, Paydar A, et al. Standardized treatment of active tuberculosis in patients with previous treatment and/or with mono-resistance to isoniazid: a systematic review and meta-analysis. PLoS Med 2009; 6: 1-14. Mota L, Al-Efraij K, Campbell JR, et al. Therapeutic drug monitoring in anti-tuberculosis treatment: a systematic review and meta-analysis. Int J Tuberc Lung Dis 2016; 20: 819-826.

79 Mwandumba HC, Squire SB. Fully intermittent dosing with drugs for treating tuberculosis in adults. Cochrane Database Syst Rev 2001; 4: CD000970.

80 Albanna AS, Smith BM, Cowan D, et al. Fixed-dose combination antituberculosis therapy: a systematic review and meta-analysis. Eur Respir J 2013; 42: 721-732.

81 Chang KC, Leung CC, Grosset J, et al. Treatment of tuberculosis and optimal dosing schedules. Thorax 2011; 66: 997-1007.

82 Si ZL, Kang LL, Shen XB, et al. Adjuvant efficacy of nutrition support during pulmonary tuberculosis treating course: systematic review and meta-analysis. Chin Med J 2015; 128: 3219-3230.

83 Sotgiu G, Matteelli A, Getahun $\mathrm{H}$, et al. Monitoring toxicity in individuals receiving treatment for latent tuberculosis infection: a systematic review versus expert opinion. Eur Respir J 2015; 45: 1170-1173.

84 Bangalore S, Kamalakkannan G, Parkar S, et al. Fixed-dose combinations improve medication compliance: a meta-analysis. Am J Med 2007; 120: 713-719.

85 Chen TC, Lu PL, Lin CY, et al. Fluoroquinolones are associated with delayed treatment and resistance in tuberculosis: a systematic review and meta-analysis. Int J Infect Dis 2011; 15: e211-e216.

86 Han T. Effectiveness of standard short-course chemotherapy for treating tuberculosis and the impact of drug resistance on its outcome. Int J Evid Based Healthcare 2006; 4: 101-117.

87 Wilby KJ, Ensom MH, Marra F. Review of evidence for measuring drug concentrations of first-line antitubercular agents in adults. Clin Pharmacokinet 2014; 53: 873-890.

88 Doherty AM, Kelly J, McDonald C, et al. A review of the interplay between tuberculosis and mental health. Gen Hosp Psychiatry 2013; 35: 398-406.

89 Baker MA, Harries AD, Jeon CY, et al. The impact of diabetes on tuberculosis treatment outcomes: a systematic review. BMC Med 2011; 9: 81.

90 M'Imunya JM, Kredo T, Volmink J. Patient education and counselling for promoting adherence to treatment for tuberculosis. Cochrane Database Syst Rev 2012; 5: CD006591.

91 Karumbi J, Garner P. Directly observed therapy for treating tuberculosis. Cochrane Database Syst Rev 2015; 5: CD003343.

92 Lewin S, Munabi-Babigumira S, Glenton C, et al. Lay health workers in primary and community health care for maternal and child health and the management of infectious diseases. Cochrane Database Syst Rev 2010; 17: CD004015.

93 Liu Q, Abba K, Alejandria MM, et al. Reminder systems to improve patient adherence to tuberculosis clinic appointments for diagnosis and treatment. Cochrane Database Syst Rev 2014; 11: CD006594.

94 Lutge EE, Wiysonge CS, Knight SE, et al. Incentives and enablers to improve adherence in tuberculosis. Cochrane Database Syst Rev 2015; 9: CD007952.

95 Mbuagbaw L, Mursleen S, Lytvyn L, et al. Mobile phone text messaging interventions for HIV and other chronic diseases: an overview of systematic reviews and framework for evidence transfer. BMC Health Serv Res 2015; 15: 33.

96 Nglazi MD, Bekker LG, Wood R, et al. Mobile phone text messaging for promoting adherence to anti-tuberculosis treatment: a systematic review. BMC Infect Dis 2013; 13: 566.

97 Tian JH, Lu ZX, Bachmann MO, et al. Effectiveness of directly observed treatment of tuberculosis: a systematic review of controlled studies. Int J Tuberc Lung Dis 2014; 18: 1092-1098.

98 Weaver MS, Lonnroth K, Howard SC, et al. Interventions to improve adherence to treatment for paediatric tuberculosis in low- and middle-income countries: a systematic review and meta-analysis. Bull World Health Organ 2015; 93: 700-711.

99 Hwang SW, Tolomiczenko G, Kouyoumdjian FG, et al. Interventions to improve the health of the homeless: a systematic review. Am J Prev Med 2005; 29: 311-319.

100 Pasipanodya JG, Gumbo T. A meta-analysis of self-administered $v$ s directly observed therapy effect on microbiologic failure, relapse, and acquired drug resistance in tuberculosis patients. Clin Infect Dis 2013; 57: $21-31$.

101 Stuurman AL, Vonk Noordegraaf-Schouten M, van Kessel F, et al. Interventions for improving adherence to treatment for latent tuberculosis infection: a systematic review. BMC Infect Dis 2016; 16: 257.

102 Chaulk CP, Kazandjian VA. Directly observed therapy for treatment completion of pulmonary tuberculosis: Consensus Statement of the Public Health Tuberculosis Guidelines Panel. JAMA 1998; 279: 943-948. 

treatment completion for antiretroviral therapy and tuberculosis treatment: a literature review. AIDS Behav 2014; 18: Suppl. 5, s531-s541.

104 Devi BR, Syed-Abdul S, Kumar A, et al. mHealth: an updated systematic review with a focus on HIV/AIDS and tuberculosis long term management using mobile phones. Comput Methods Programs Biomed 2015; 122: 257-265.

105 Herrmann ES, Matusiewicz AK, Stitzer ML, et al. Contingency management interventions for HIV, tuberculosis, and hepatitis control among individuals with substance use disorders: a systematized review. J Subst Abuse Treat 2017; 72: 117-125.

106 Hirsch-Moverman Y, Daftary A, Franks J, et al. Adherence to treatment for latent tuberculosis infection: systematic review of studies in the US and Canada. Int J Tuberc Lung Dis 2008; 12: 1235-1254.

107 Krishna S, Balas EA, Boren SA, et al. Patient acceptance of educational voice messages: a review of controlled clinical studies. Methods Inf Med 2002; 41: 360-369.

108 Peterson AM, Takiya L, Finley R. Meta-analysis of trials of interventions to improve medication adherence. Am J Health Syst Pharm 2003; 60: 657-665.

109 Petry NM, Rash CJ, Byrne S, et al. Financial reinforcers for improving medication adherence: findings from a meta-analysis. Am J Med 2012; 125: 888-896.

110 Sallum RH, Travers KU, Kalsekar A, et al. The impact of directly observed therapy (DOT) in patients with tuberculosis. Value Health 2011; 14: A267.

111 Ershad Sarabi R, Sadoughi F, Orak RJ, et al. The effectiveness of mobile phone text messaging in improving medication adherence for patients with chronic diseases: a systematic review. Iran Red Crescent Med J 2016; 18: e25183.

112 Schroeder JR, Donath E, Sarmento B. Evaluating the risk of study withdrawal among treatment regimens for latent tuberculosis: a network meta-analysis. Am J Respir Crit Care Med 2013; 187: A3186.

113 Suwannakeeree W, Picheansathian W. Strategies to promote adherence to treatment by pulmonary tuberculosis patients: a systematic review. Int J Evid Based Healthcare 2014; 12: 3-16.

114 Munro SA, Lewin SA, Smith HJ, et al. Patient adherence to tuberculosis treatment: a systematic review of qualitative research. PLoS Med 2007; 4: e238.

115 Akolo C, Adetifa I, Shepperd S, et al. Treatment of latent tuberculosis infection in HIV infected persons. Cochrane Database Syst Rev 2010; 1: CD000171.

116 Gray DM, Zar H, Cotton M. Impact of tuberculosis preventive therapy on tuberculosis and mortality in HIV-infected children. Cochrane Database Syst Rev 2009; 1: CD006418.

117 Suthar AB, Lawn SD, del Amo J, et al. Antiretroviral therapy for prevention of tuberculosis in adults with HIV: a systematic review and meta-analysis. PLoS Med 2012; 9: e1001270.

118 Bruins WS, van Leth F. Effect of secondary preventive therapy on recurrence of tuberculosis in HIV-infected individuals: a systematic review. Infect Dis (Lond) 2017; 49: 161-169.

119 Bucher HC, Griffith LE, Guyatt GH, et al. Isoniazid prophylaxis for tuberculosis in HIV infection: a meta-analysis of randomized controlled trials. AIDS 1999; 13: 501-507.

120 Ayele HT, Mourik MS, Debray TP, et al. Isoniazid prophylactic therapy for the prevention of tuberculosis in HIV infected adults: a systematic review and meta-analysis of randomized trials. PLoS One 2015; 10: e0142290.

121 B-Lajoie MR, Drouin O, Bartlett G, et al. Incidence and prevalence of opportunistic and other infections and the impact of antiretroviral therapy among HIV-infected children in low- and middle-income countries: a systematic review and meta-analysis. Clin Infect Dis 2016; 62: 1586-1594.

122 Dodd PJ, Prendergast AJ, Beecroft C, et al. The impact of HIV and antiretroviral therapy on TB risk in children: a systematic review and meta-analysis. Thorax 2017; 72: 559-575.

123 Low A, Gavriilidis G, Larke N, et al. Incidence of opportunistic infections and the impact of antiretroviral therapy among HIV-infected adults in low- and middle-income countries: a systematic review and meta-analysis. Clin Infect Dis 2016; 62: 1595-1603.

124 Ayubi E, Doosti-Irani A, Sanjari Moghaddam A, et al. The clinical usefulness of tuberculin skin test versus interferon-gamma release assays for diagnosis of latent tuberculosis in HIV patients: a meta-analysis. PLoS One 2016; 11: e0161983.

125 Kerkhoff AD, Kranzer K, Samandari T, et al. Systematic review of TST responses in people living with HIV in under-resourced settings: implications for isoniazid preventive therapy. PLoS One 2012; 7: e49928.

126 Wikman-Jorgensen P, Llenas-Garcia J, Hobbins M, et al. Microscopic observation drug susceptibility assay for the diagnosis of TB and MDR-TB in HIV-infected patients: a systematic review and meta-analysis. Eur Respir J 2014; 44: 973-984.

127 Arentz M, Pavlinac P, Kimerling ME, et al. Use of anti-retroviral therapy in tuberculosis patients on second-line anti-TB regimens: a systematic review. PLoS One 2012; 7: e47370.

128 Cattamanchi A, Smith R, Steingart KR, et al. Interferon-gamma release assays for the diagnosis of latent tuberculosis infection in HIV-infected individuals: a systematic review and meta-analysis. J Acquir Immune Defic Syndr 2011; 56: 230-238.

129 Legido-Quigley H, Montgomery CM, Khan P, et al. Integrating tuberculosis and HIV services in low- and middle-income countries: a systematic review. Trop Med Int Health 2013; 18: 199-211.

130 Fraser A, Paul M, Attamna A, et al. Drugs for preventing tuberculosis in people at risk of multiple-drug-resistant pulmonary tuberculosis. Cochrane Database Syst Rev 2006: 2; CD005435.

131 Langendam MW, Tiemersma EW, van der Werf MJ, et al. Adverse events in healthy individuals and MDR-TB contacts treated with anti-tuberculosis drugs potentially effective for preventing development of MDR-TB: a systematic review. PLoS One 2013; 8: e53599.

132 van der Werf MJ, Langendam MW, Sandgren A, et al. Lack of evidence to support policy development for management of contacts of multidrug-resistant tuberculosis patients: two systematic reviews. Int J Tuberc Lung Dis 2012; 16: 288-296.

133 Marks SM, Mase SR, Bamrah M. Systematic review, meta-analysis, and cost effectiveness of treatment of latent tuberculosis infection to reduce progression to multidrug-resistant tuberculosis. Clin Infect Dis 2017; 64: 1670-1677.

134 Ahuja SD, Ashkin D, Avendano M, et al. Multidrug resistant pulmonary tuberculosis treatment regimens and patient outcomes: an individual patient data meta-analysis of 9,153 patients. PLoS Med 2012; 9: e1001300. 
Chang KC, Yew WW, Tam CM, et al. WHO group 5 drugs and difficult multidrug-resistant tuberculosis: a systematic review with cohort analysis and meta-analysis. Antimicrob Agents Chemother 2013; 57: 4097-4104.

Fox GJ, Benedetti A, Cox H, et al. Group 5 drugs for multidrug-resistant tuberculosis: individual patient data meta-analysis. Eur Respir J 2017; 49: 1600993.

Bassili A, Fitzpatrick C, Qadeer E, et al. A systematic review of the effectiveness of hospital- and ambulatorybased management of multidrug-resistant tuberculosis. Am J Trop Med Hyg 2013; 89: 271-280.

Bastos ML, Hussain H, Weyer K, et al. Treatment outcomes of patients with multidrug-resistant and extensively drug-resistant tuberculosis according to drug susceptibility testing to first- and second-line drugs: an individual patient data meta-analysis. Clin Infect Dis 2014; 59: 1364-1374.

Bastos ML, Lan Z, Menzies D. An updated systematic review and meta-analysis for treatment of multidrug-resistant tuberculosis. Eur Respir J 2017; 49 :1600803.

Ettehad D, Schaaf HS, Seddon JA, et al. Treatment outcomes for children with multidrug-resistant tuberculosis: a systematic review and meta-analysis. Lancet Infect Dis 2012; 12: 449-456.

Falzon D, Gandhi N, Migliori GB, et al. Resistance to fluoroquinolones and second-line injectable drugs: impact on multidrug-resistant TB outcomes. Eur Respir J 2013; 42: 156-168.

Fox GJ, Benedetti A, Mitnick CD, et al. Propensity score-based approaches to confounding by indication in individual patient data meta-analysis: non-standardized treatment for multidrug resistant tuberculosis. PLoS One 2016; 11: e0151724.

Ghimire S, Van't Boveneind-Vrubleuskaya N, Akkerman OW, et al. Pharmacokinetic/pharmacodynamic-based optimization of levofloxacin administration in the treatment of MDR-TB. J Antimicrob Chemother 2016; 71: 2691-2703.

Ho J, Byrne AL, Linh NN, et al. Decentralized care for multidrug-resistant tuberculosis: a systematic review and meta-analysis. Bull World Health Organ 2017; 95: 584-593.

Kibret KT, Moges Y, Memiah P, et al. Treatment outcomes for multidrug-resistant tuberculosis under DOTS-Plus: a systematic review and meta-analysis of published studies. Infect Dis Poverty 2017; 6: 7. Orenstein EW, Basu S, Shah NS, et al. Treatment outcomes among patients
systematic review and meta-analysis. Lancet Infect Dis 2009; 9: 153-161.

Thomas BE, Shanmugam P, Malaisamy M, et al. Psycho-socio-economic issues challenging multidrug resistant tuberculosis patients: a systematic review. PLoS One 2016; 11: e0147397.

Toczek A, Cox $\mathrm{H}$, du Cros $\mathrm{P}$, et al. Strategies for reducing treatment default in drug-resistant tuberculosis: systematic review and meta-analysis. Int J Tuberc Lung Dis 2013; 17: 299-307.

Weiss P, Chen W, Cook VJ, et al. Treatment outcomes from community-based drug resistant tuberculosis treatment programs: a systematic review and meta-analysis. BMC Infect Dis 2014; 14: 333.

Yin J, Yuan J, Hu Y, et al. Association between directly observed therapy and treatment outcomes in multidrug-resistant tuberculosis: a systematic review and meta-analysis. PLoS One 2016; 11: e0150511.

Nikolayevskyy V, Kranzer K, Niemann S, et al. Whole genome sequencing of Mycobacterium tuberculosis for detection of recent transmission and tracing outbreaks: a systematic review. Tuberculosis (Edinb) 2016; 98: $77-85$. tuberculosis: systematic review and meta-analysis. Clin Infect Dis 2014; 58: 381-391.

Hatherell HA, Colijn C, Stagg HR, et al. Interpreting whole genome sequencing for investigating tuberculosis transmission: a systematic review. BMC Med 2016; 14: 21.

Fair E, Miller C, Cattamanchi A, et al. Systematic review of tuberculosis contact investigation in low-and middleincome countries: an update. In: Recommendations for Investigating Contacts of Persons with Infectious Tuberculosis in Low- and Middle-Income Countries. Geneva, World Health Organization, 2012.

Fox GJ, Barry SE, Britton WJ, et al. Contact investigation for tuberculosis: a systematic review and meta-analysis. Eur Respir J 2013; 41: 140-156.

Zenner D, Southern J, van Hest R, et al. Active TB case finding strategies in high-risk groups in low-incidence countries. Int J Tuberuc Lung Dis 2013; 17: 573-582.

Abubakar I. Tuberculosis and air travel: a systematic review and analysis of policy. Lancet Infect Dis 2010; 10: 176-183. Freeman RJ, Mancuso JD, Riddle MS, et al. Systematic review and meta-analysis of TST conversion risk in deployed military and long-term civilian travelers. J Travel Med 2010; 17: 233-242.

Kotila SM, Payne Hallstrom L, Jansen N, et al. Systematic review on tuberculosis transmission on aircraft and update of the European Centre for Disease Prevention and Control risk assessment guidelines for tuberculosis transmitted on aircraft (RAGIDA-TB). Euro Surveill 2016; 21: 21357-21357.

0 Yassi A, O'Hara LM, Lockhart K, et al. Workplace programmes for HIV and tuberculosis: a systematic review to support development of international guidelines for the health workforce. AIDS Care 2013; 25: 525-543.

World Health Organization. Use of tuberculosis interferon-gamma release assays (IGRAs) in low- and middle-income countries: policy statement. Geneva, World Health Organization, 2011.

Wisnivesky JP, Serebrisky D, Moore C, et al. Validity of clinical prediction rules for isolating inpatients with suspected tuberculosis. A systematic review. J Gen Intern Med 2005; 20: 947-952.

Solari L, Acuna-Villaorduna C, Soto A, et al. Evaluation of clinical prediction rules for respiratory isolation of inpatients with suspected pulmonary tuberculosis. Clin Infect Dis 2011; 52: 595-603.

Lamberti M, Uccello R, Monaco MGL, et al. Tuberculin skin test and Quantiferon test agreement and influencing factors in tuberculosis screening of healthcare workers: a systematic review and meta-analysis. $J$ Occup Med Toxicol 2015; 10: 2.

Nienhaus A, Ringshausen FC, Costa JT, et al. IFN-gamma release assay versus tuberculin skin test for monitoring TB infection in healthcare workers. Expert Rev Anti Infect Ther 2013; 11: 37-48.

Zwerling A, van den Hof S, Scholten J, et al. Interferon-gamma release assays for tuberculosis screening of healthcare workers: a systematic review. Thorax 2012; 67: 62-70.

Esquinas AM, Pravinkumar SE, Scala R, et al. Non-invasive mechanical ventilation in high-risk pulmonary infections: a clinical review. Eur Respir Rev 2014; 23: 427-438.

Kramer A, Schwebke I, Kampf G. How long do nosocomial pathogens persist on inanimate surfaces? A systematic review. BMC Infect Dis 2006; 6: 130. 

Assess Series 2012; 5: 1.

170 Schepisi MS, Sotgiu G, Contini S, et al. Tuberculosis transmission from healthcare workers to patients and co-workers: a systematic literature review and meta-analysis. PLoS One 2015; 10: e0121639.

171 Heuvelings CC, de Vries SG, Greve PF, et al. Effectiveness of interventions for diagnosis and treatment of tuberculosis in hard-to-reach populations in countries of low and medium tuberculosis incidence: a systematic review. Lancet Infect Dis 2017; 17: e144-e158.

172 Arshad A, Salam RA, Lassi ZS, et al. Community based interventions for the prevention and control of tuberculosis. Infect Dis Poverty 2014; 3: 27.

173 van Hoorn R, Jaramillo E, Collins D, et al. The effects of psycho-emotional and socio-economic support for tuberculosis patients on treatment adherence and treatment outcomes - a systematic review and meta-analysis. PLoS One 2016; 11: e0154095.

174 Grenfell P, Baptista Leite R, Garfein R, et al. Tuberculosis, injecting drug use and integrated HIV-TB care: a review of the literature. Drug Alcohol Depend 2013; 129: 180-209.

175 National Institute for Health and Care Excellence. Tuberculosis: NICE guideline NG33. London, NICE, 2016.

176 Cobelens F, van Kampen S, Ochodo E, et al. Research on implementation of interventions in tuberculosis control in low- and middle-income countries: a systematic review. PLoS Med 2012; 9: e1001358.

177 Lei X, Liu Q, Escobar E, et al. Public-private mix for tuberculosis care and control: a systematic review. Int J Infect Dis 2015; 34: 20-32.

178 Seidman G, Atun R. Does task shifting yield cost savings and improve efficiency for health systems? A systematic review of evidence from low-income and middle-income countries. Hum Resour Health 2017; 15: 29.

179 Wu S, Roychowdhury I, Khan M. Evaluating the impact of healthcare provider training to improve tuberculosis management: a systematic review of methods and outcome indicators used. Int J Infect Dis 2017; 56: 105-110.

180 Floyd K. Costs and effectiveness - the impact of economic studies on TB control. Tuberculosis (Edinb) 2003; 83: $187-200$.

181 Alsdurf H, Hill PC, Matteelli A, et al. The cascade of care in diagnosis and treatment of latent tuberculosis infection: a systematic review and meta-analysis. Lancet Infect Dis 2016; 16: 1269-1278.

182 Nguyen HT, Pandolfini C, Chiodini P, et al. Tuberculosis care for pregnant women: a systematic review. BMC Infect Dis 2014; 14: 617.

183 Malhame I, Cormier M, Sugarman J, et al. Latent tuberculosis in pregnancy: a systematic review. PLoS One 2016; 11: $\mathrm{e} 0154825$

184 Moradi B, Meshkat Z. Evaluation of tuberculosis infection in pregnant women and its effects on newborns: an overview. Iranian J Obst Gynecol Infert 2015; 18: 21-36.

185 Repossi AC, Bothamley GH. Tuberculosis and pregnancy: an updated systematic review. Pulmon Res Respir Med Open J 2015; 2: 63-68.

186 Sudhakar M, Admassu B. Determinants of help seeking and treatment seeking behavior of tuberculosis patients gender perspective: a systematic review. JBI Database Syst Rev Implement Rep 2013; 11: 199-271.

187 van den Hof S, Najlis CA, Bloss E, et al. A systematic review on the role of gender in tuberculosis control, 2010. www.tbcare1.org/publications/toolbox/tools/access/Role_of_Gender_in_TB_Control.pdf

188 Al-Darraji HA, Kamarulzaman A, Altice FL. Isoniazid preventive therapy in correctional facilities: a systematic review. Int J Tuberc Lung Dis 2012; 16: 871-879.

189 Vinkeles Melchers NV, van Elsland SL, Lange JM, et al. State of affairs of tuberculosis in prison facilities: a systematic review of screening practices and recommendations for best TB control. PLoS One 2013; 8: e53644.

190 Baussano I, Williams BG, Nunn P, et al. Tuberculosis incidence in prisons: a systematic review. PLoS Med 2010; 7: e1000381.

191 Bates MN, Khalakdina A, Pai M, et al. Risk of tuberculosis from exposure to tobacco smoke: a systematic review and meta-analysis. Arch Intern Med 2007; 167: 335-342.

192 Dogar OF, Pillai N, Safdar N, et al. Second-hand smoke and the risk of tuberculosis: a systematic review and a meta-analysis. Epidemiol Infect 2015; 143: 3158-3172.

193 Jafta N, Jeena PM, Barregard L, et al. Childhood tuberculosis and exposure to indoor air pollution: a systematic review and meta-analysis. Int J Tuberc Lung Dis 2015; 19: 596-602.

194 Jayes L, Haslam PL, Gratziou CG, et al. SmokeHaz: systematic reviews and meta-analyses of the effects of smoking on respiratory health. Chest 2016; 150: 164-179.

195 Kurmi OP, Sadhra CS, Ayres JG, et al. Tuberculosis risk from exposure to solid fuel smoke: a systematic review and meta-analysis. J Epidemiol Community Health 2014; 68: 1112-1118.

196 Lin HH, Ezzati M, Murray M. Tobacco smoke, indoor air pollution and tuberculosis: a systematic review and meta-analysis. PLoS Med 2007; 4: e20.

197 Lonnroth K, Williams BG, Stadlin S, et al. Alcohol use as a risk factor for tuberculosis: a systematic review. BMC Public Health 2008; 8: 289.

198 Patra J, Bhatia M, Suraweera W, et al. Exposure to second-hand smoke and the risk of tuberculosis in children and adults: a systematic review and meta-analysis of 18 observational studies. PLoS Med 2015; 12 : e1001835.

199 Slama K, Chiang CY, Enarson DA, et al. Tobacco and tuberculosis: a qualitative systematic review and meta-analysis. Int J Tuberc Lung Dis 2007; 11: 1049-1061.

200 Sumpter C, Chandramohan D. Systematic review and meta-analysis of the associations between indoor air pollution and tuberculosis. Trop Med Int Health 2013; 18: 101-108.

201 Underner M, Perriot J, Peiffer G, et al. Smoking and adherence to anti-tuberculosis treatment. Rev Mal Respir 2016; 33: 128-144.

202 National Institute for Health and Care Excellence. Evidence review on the effectiveness and cost-effectiveness of interventions aimed at identifying people with tuberculosis and/or raising awareness of tuberculosis among hard-to-reach groups. London, NICE, 2011.

203 National Institute for Health and Care Excellence. Evidence review on the effectiveness and cost-effectiveness of interventions aimed at managing tuberculosis in hard-to-reach groups. London, NICE, 2011.

204 Diez E, Claveria J, Serra T, et al. Evaluation of a social health intervention among homeless tuberculosis patients. Tuber Lung Dis 1996; 77: 420-424. 
Reeves A, Basu S, McKee M, et al. Tuberculosis control and economic recession: longitudinal study of data from 21 European countries, 1991-2012. Bull World Health Organ 2015; 93: 369-379.

206 de Vries G, van Dissel J, van Soolingen D. Measuring tuberculosis transmission in low-incidence countries. Lancet Respir Med 2018; 6: e13.

207 Mangtani P, Nguipdop-Djomo P, Keogh RH, et al. The duration of protection of school-aged BCG vaccination in England: a population-based case-control study. Int J Epidemiol 2018; 47: 193-201.

208 Mangtani P, Nguipdop-Djomo P, Keogh RH, et al. Observational study to estimate the changes in the effectiveness of bacillus Calmette-Guerin (BCG) vaccination with time since vaccination for preventing tuberculosis in the UK. Health Technol Assess 2017; 21: 1-54.

209 Van Der Meeren O, Hatherill M, Nduba V, et al. Phase 2b controlled trial of M72/AS01E vaccine to prevent tuberculosis. N Engl J Med 2018; 379: 1621-1634.

210 Kendall EA, Fojo AT, Dowdy DW. Expected effects of adopting a 9 month regimen for multidrug-resistant tuberculosis: a population modelling analysis. Lancet Respir Med 2017; 5: 191-199.

211 Dobler CC, Fox GJ, Douglas P, et al. Screening for tuberculosis in migrants and visitors from high-incidence settings: present and future perspectives. Eur Respir J 2018; 52: 1800591.

212 Loutet MG, Burman M, Jayasekera N, et al. National roll-out of latent tuberculosis testing and treatment for new migrants in England: a retrospective evaluation in a high-incidence area. Eur Respir J 2018; 51 : 1701226.

213 van de Berg S, Erkens C, van Rest J, et al. Evaluation of tuberculosis screening of immigrants in the Netherlands. Eur Respir J 2017; 50: 1700977.

214 Zenner D, Loutet MG, Harris R, et al. Evaluating 17 years of latent tuberculosis infection screening in north-west England: a retrospective cohort study of reactivation. Eur Respir J 2017; 50: 1602505.

215 World Health Organization. Latent TB infection: updated and consolidated guidelines for programmatic management. Geneva, World Health Organization, 2018.

216 World Health Organization. Guidelines for treatment of drug-susceptible tuberculosis and patient care. Geneva, World Health Organization, 2018.

217 Nicolau I, Ling D, Tian L, et al. Methodological and reporting quality of systematic reviews on tuberculosis. Int $J$ Tuberc Lung Dis 2013; 17: 1160-1169.

218 Tharyan P. Introducing conceptual and analytical clarity on dimensions of complexity in systematic reviews of complex interventions. J Clin Epidemiol 2013; 66: 1202-1204.

219 Collin S, Zenner D, Abubakar I, et al. 2017. Barriers and facilitators to TB control and prevention in Europe: a systematic review of complex interventions. www.crd.york.ac.uk/PROSPERO/display_record.php?RecordID=60100

220 de Vries SG, Cremers AL, Heuvelings CC, et al. Barriers and facilitators to the uptake of tuberculosis diagnostic and treatment services by hard-to-reach populations in countries of low and medium tuberculosis incidence: a systematic review of qualitative literature. Lancet Infect Dis 2017; 17: e128-e143.

221 Migliori GB, Sotgiu G, Rosales-Klintz S, et al. ERS/ECDC Statement: European Union standards for tuberculosis care, 2017 update. Eur Respir J 2018; 51: 1702678. 